Eberhart, B. M. \& Tatum, E. L. (1959). J. gen. Microbiol. 20, 43-53

\title{
A Gene Modifying the Thiamine-requirement of Strains of Neurospora crassa
}

\author{
By B. M. EBERHART* aND E. L. TATUM ${ }^{*}$ \\ Department of Biological Sciences, Stanford University, Stanford, California, \\ U.S.A.
}

SUMMARY: A new gene, thi-1o, is described in Neurospora crassa. This gene is shown to be a modifier of the nutritional response of strains containing the thi-1 gene, and is not nutritionally detectable in the absence of the thi-1 mutant locus. The gene $t h i-10$ is additionally characterized by a decreased ability to synthesize thiamine from thiazole and pyrimidine; thi-1o appears to modify only thi-1 strains because of their unusually high thiamine requirements. The nutritional responses of strains containing either thi-2 or thi-3 loci are not affected by the presence of thi-1o. Both thi-1o and thi-4 are anomalous in the condensation of pyrimidine and thiazole. The probability that thi-1o may be an isoallele of $t h i-4$ is based upon a similarity of metabolic pattern and upon location on chromosome III. The failure to obtain recombination in crosses between strains containing $t h i-10$ and $t h i-4$ constitutes additional support for their allelism.

The metabolic pathway of thiamine synthesis in Neurospora is not entirely agreed upon. Tatum \& Bell (1946) concluded that thiamine is derived by a condensation of substances equivalent to vitamin pyrimidine (2-methyl-4amino-5-ethoxymethyl pyrimidine) and vitamin thiazole (4-methyl-5- $\beta$ hydroxyethyl thiazole). In subsequent work, Harris (1953) stated that such a scheme does not account for the requirements and the accumulation products of the Neurospora thiamine-requiring mutants. Harris (1955) also proposed an alternative scheme in which a pyrimidine-incomplete-thiazole intermediate is formed prior to the formation of intact thiamine. The quantitative nutritional response of the thiamineless strains is critical in the formulation of either of these alternative proposals. According to Barratt, Newmeyer, Perkins \& Garnjobst (1954), the various thiamine-requiring strains of Neurospora have these qualities:

\begin{tabular}{ccccccc} 
& \multicolumn{4}{c}{ Growth responses } \\
Symbol & $\begin{array}{c}\text { Isolation } \\
\text { no. }\end{array}$ & $\begin{array}{l}\text { Linkage } \\
\text { group }\end{array}$ & Thiamine & Thiazole & Pyrimidine & $\begin{array}{c}\text { Pyrimidine } \\
\text { \& thiazole }\end{array}$ \\
thi-1 & $\mathbf{5 6 5 0 1 / 1 7 0 8 4}$ & I & + & - & - & + \\
thi-2 & $\mathbf{9 1 8 5}$ & III & + & - & - & - \\
thi-3 & $\mathbf{1 8 5 5 8}$ & VII & + & + & - & + \\
thi-4 & $\mathbf{8 5 9 0 2}$ & III & + & - & - & -
\end{tabular}

As part of the continued investigation of this problem (Eberhart, 1956), several thiamineless strains have been examined for the presence of modifying

* Present address : Department of Biology, Princeton University, Princeton, N.J., U.S.A.

$\dagger$ Present address: Rockefeller Institute of Medical Research, New York, New York, U.S.A. 
genes which might affect quantitative or qualitative requirements of these thiamineless mutants. Although no modifiers were found which contribute to a re-evaluation of the thiamine metabolism in Neurospora, a gene modifying the thi-1 locus was found in certain wild-type strains. The purpose of this paper is to describe this new gene, thi-1o, in terms of its genetic behaviour and metabolic expression.

\section{METHODS}

The basal medium for growing Neurospora was that of Beadle \& Tatum (1945). Crosses were made using the chemically defined medium of Westergaard \& Mitchell (1947).

Cocarboxylase determinations essentially followed the procedure of Westenbrink \& Steyn-Parvé (1950) as follows: $1 \mathrm{~g}$. dried yeast* was suspended in $20 \mathrm{ml}$. of tris (2-amino-2-hydroxymethyl propane-1:3-diol; Sigma Chemical Co., St Louis, Mo.) buffer at pH 9.0 (0.1 M). The preparation was centrifuged, and three similar washings with distilled water followed quickly. For optimal results this procedure took no more than $30 \mathrm{~min}$. The yeast was then suspended in phosphate buffer $(\mathrm{pH} 6 \cdot 2,0 \cdot 1 \mathrm{M})$ with a final volume of $12 \mathrm{ml}$. One $\mathrm{ml}$. of a $0 \cdot 1 \mathrm{M}$-magnesium chloride solution was added, followed by $1 \mathrm{ml}$. of a thiamine solution (equiv. $100 \mu \mathrm{g}$. thiamine). The yeast preparation was stored at $5^{\circ}$ until used within $24 \mathrm{hr}$.). Storage by freezing destroyed only half of the carboxylase activity. One-half $\mathrm{ml}$. of this preparation was added to each Warburg flask (total volume $3 \mathrm{ml}$.). The substrate consisted of $0.2 \mathrm{ml}$. of a $2 \%$ $(\mathrm{w} / \mathrm{v})$ pyruvate solution.

Thiamine and thiamine pyrophosphate were determined by the thiochrome technique of Stiller (1950). Thiochrome was assayed in a Nefluorophotometer (Fisher Scientific Co., New York, N.Y.). In experiments in which the thiamine concentrations were high, direct water-phase thiochrome determinations were successful without the usual isobutanol extraction.

Thiamine synthesis and thiamine phosphorylation were measured by the incorporation of exogenous thiazole and pyrimidine or of thiamine into 'bound ' thiamine (i.e. thiochrome not soluble in isobutanol) in mycelia of optimally grown strains of Neurospora. Typically, $5 \mu \mathrm{g}$. thiamine/100 ml. were included in the growth media of all strains tested. The strains were grown with agitation for $40 \mathrm{hr}$. at $30^{\circ}$ (exceptions are noted), and filter-sterilized thiazole and pyrimidine or thiamine were then added. After further incubation, the extracts were examined for 'bound' thiamine and for total thiamine (thiochrome soluble after takadiastase treatment).

Air-dried mycelia with carboxylase activity were prepared from Neurospora cultures which were filtered on paper in a Buchner funnel, and washed with three volumes of distilled water. During the final washing the mycelia were suspended so that the resulting pad was spread evenly on the filterpaper. The damp mycelial pad was removed from the funnel and placed on a

* The authors had no success with dried 'Active' Bakers' yeast preparations, but found air dried Brewers' yeast (Falstaff of San Jose, California) to be satisfactory for cocarboxylase determination. 
glass surface. The pad was gently pressed so that it would stick to the glass, and an air stream from an electric fan was used to dry the pad as quickly as possible. When thoroughly dry (coolness of the pad indicates evaporation is still in progress) the mycelial pad was removed from the glass, weighed, and stored in a desiccator in the dark. Mycelial preparations of this type retain carboxylase activity for as long as a year.

The carboxylase activity of dry Neurospora mycelia was measured in a Warburg-Barcroft manometer. Weighed samples of mycelium (about $20 \mathrm{mg}$.) were placed in the manometer flask, and $2.8 \mathrm{ml}$. of $0.1 \mathrm{M}$-phosphate buffer ( $\mathrm{pH} \mathrm{5.6)}$ were added. Pyruvate substrate solution $(0.2 \mathrm{ml}$. of a $2 \%, \mathrm{w} / \mathrm{v}$, solution) was added to the side arm. When the closed manometric system reached equilibrium in $\mathbf{3} 33^{\circ}$ water bath, the substrate was added and readings were taken at $5 \mathrm{~min}$. intervals. The first three readings were critical because of the inhibitory effects of the acetaldehyde produced from the pyruvate.

The strains of Neurospora crassa used in this study were: (wild types) STA, STa, SY7A, SY4a, (thiamine mutants) 56501 a (thi-1), 17084-44602 (thi-1, pyridoxine), $9185 \mathrm{~A}(t h i-2), 18558 \mathrm{a}(t h i-3), 85902 \mathrm{~A}(t h i-4)$. All other strains are derived from crosses of the above strains (Table 1). These strains were obtained from the lyophilized collection at Stanford University, California.

Table 1. Crosses described in the test

\begin{tabular}{|c|c|c|c|c|c|c|}
\hline \multirow[b]{2}{*}{ Cross no. } & \multirow[b]{2}{*}{ Strains in cross } & \multicolumn{5}{|c|}{ Type of auxotrophy* } \\
\hline & & $\begin{array}{l}\text { Proto- } \\
\text { trophs }\end{array}$ & $\begin{array}{l}\text { Auxo- } \\
\text { trophs }\end{array}$ & $\begin{array}{c}B_{1} \text { or } \\
T z+P y\end{array}$ & $\mathbf{B}_{1}$ & $B_{1}$ or $T z$ \\
\hline $56501-3$ & $\begin{array}{l}56501 \text { a } \times \text { SY7 A } \\
(t h i-1 \times \text { thi-1o })\end{array}$ & 59 & 59 & 37 & 22 & - \\
\hline $56501-6$ & $\begin{array}{l}56501-3-69 \mathrm{~A} \times 9185 \mathrm{a} \\
(\text { thi-1; thi-10 } \times \text { thi-2) }\end{array}$ & 47 & 46 & 46 & 5 & 41 \\
\hline $56501-7$ & 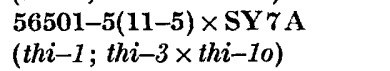 & \multicolumn{2}{|c|}{ (See text) } & & & \\
\hline $56501-17$ & $\begin{array}{l}\mathbf{5 6 5 0 1 - 3 - 9 0 A} \times 56501-3-88 \mathbf{a} \\
(t h i-1 \times t h i-1 ; \text { thi-1o) }\end{array}$ & - & - & - & - & - \\
\hline $18558-1$ & 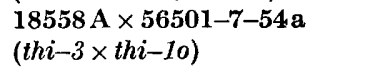 & 35 & $\mathbf{3 4}$ & - & 一 & 34 \\
\hline $85902-2$ & $\begin{array}{l}85902 \mathrm{~A} \times 56501-3-88 \mathbf{a} \\
(\text { thi-4 } \times \text { thi-1; thi-1o) }\end{array}$ & 15 & 55 & - & $\mathbf{5 5} \dagger$ & - \\
\hline $85902-3$ & $\begin{array}{l}85902 \mathrm{~A} \times 56501-3-93 \mathrm{a} \\
(\text { thi-4 } \times \text { thi-1) }\end{array}$ & 26 & 64 & 28 & 36 & - \\
\hline $9185-1$ & $\begin{array}{l}\text { STA } \times 9185 \mathbf{a} \\
(\text { wild } \times \text { thi-2) }\end{array}$ & $\mathbf{0}$ & 69 & 一 & 69 & - \\
\hline
\end{tabular}

\section{RESULTS}

Since the possibility of the existence of modifier genes in thi-1 stocks had never been adequately investigated, a cross of $t h i-1$ and wild type SY 7 A was made (cross 56501-3). In the random isolates of this cross a number of novel thiamine-requiring strains were found, which were characterized by their inability to grow on thiazole and pyrimidine (either together or separately) in a 
standard 3-day assay at $25^{\circ}$. The requirements of these new strains were therefore qualitatively similar to those of $t h i-2$ or thi-4 strains, while their quantitative responses to intact thiamine remained quite characteristic of normal thi-1 strains (Table 2). Subsequent investigation showed that a new gene, thi-1o, is responsible for this modification of the thi-1 phenotype in these unusual strains. This gene apparently came from SY7A stocks.

Table 2. The growth response of isolates from cross 56501-3

Test cultures grown three days at $25^{\circ}$ in $20 \mathrm{ml}$. minimal with supplements noted above.

Isolate number

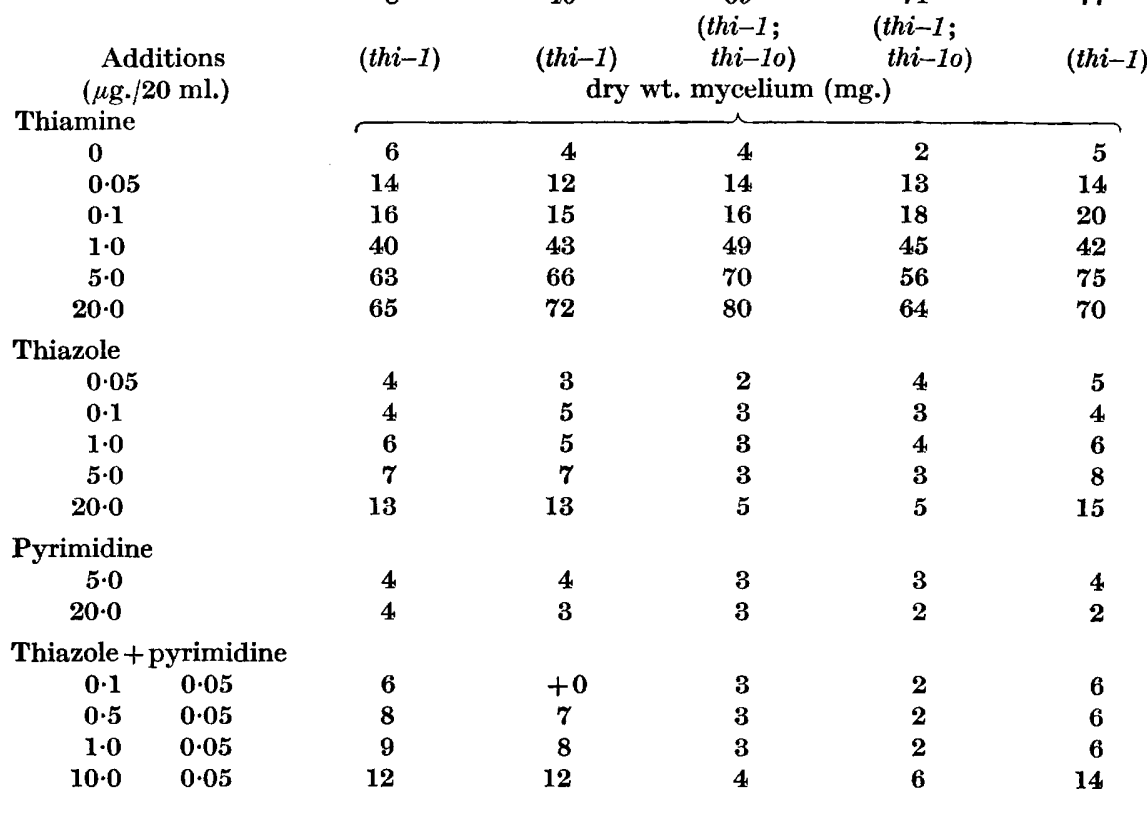

\section{Mechanism of thi-1o action}

Additional insight into the metabolic basis of the thi-1o modifier was sought by studying the thiamine synthesizing abilities of various strains containing the thi-1o modifier. The steps involved in the biological condensation of thiazole with pyrimidine, and the subsequent phosphorylation of thiamine, were investigated directly. In designing a test system for the in vivo thiamine metabolism of these strains, there were certain general considerations involved. The in vivo thiamine metabolism has at least three steps: the condensation of thiazole with pyrimidine, the phosphorylation of thiamine, and the binding of thiamine diphosphate within the cell. Since it is not yet possible to block any of these steps successfully without interfering with metabolism in general, an examination of the over-all system is required.

For example, the thiazole-pyrimidine condensing system must be measured in terms of 'bound' thiamine, because the ability of Neurospora strains to 
phosphorylate and maintain thiamine becomes a potentially limiting factor when bound thiamine is used as an index of pyrimidine and thiazole condensation. The fate of exogenous thiamine was, therefore, considered to be the first logical step in the study of these systems. Figure 1 illustrates the ability of several Neurospora strains to take up and maintain thiamine. Each culture was grown for $40 \mathrm{hr}$. at $30^{\circ}$ on minimal medium $+0 \cdot 05 \mu \mathrm{g}$. thiamine $/ \mathrm{ml}$. and then incubated with $50 \mu \mathrm{g}$. thiamine. The uptake and maintenance of thiamine by these strains are quite similar despite their extremely different thiamine requirements.

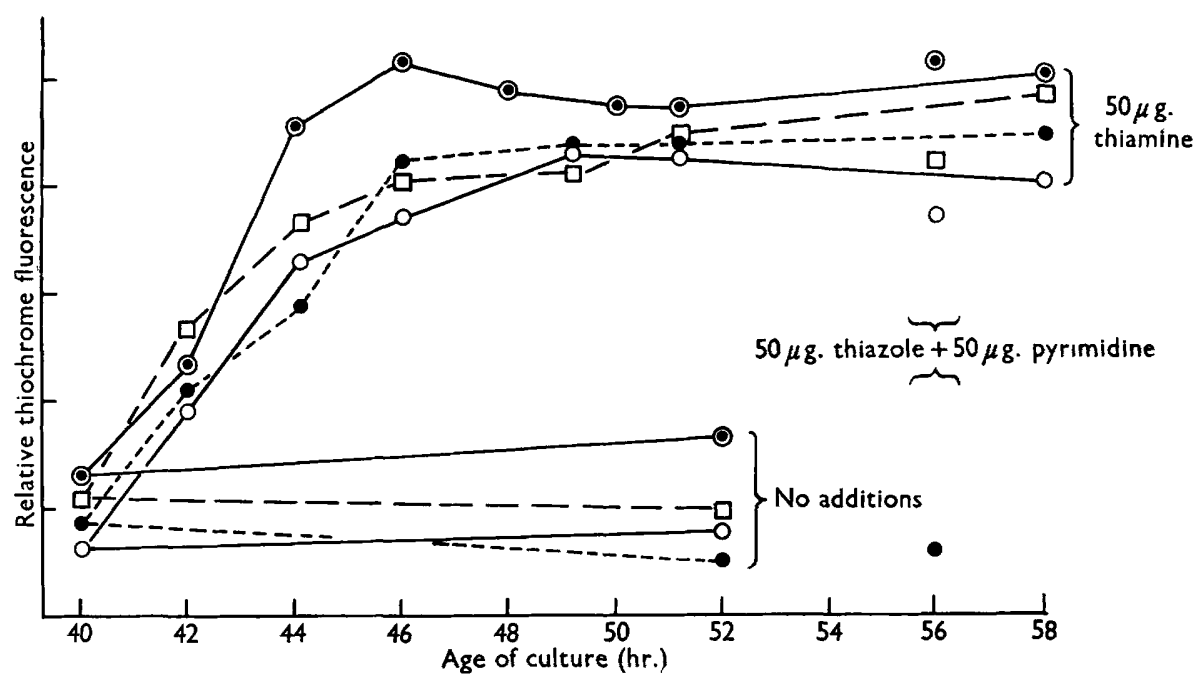

Fig. 1. Thiamine synthesis by Neurospora. Cultures were grown $40 \mathrm{hr}$. at $30^{\circ}$ with $2 \cdot 5 \mu \mathrm{g}$. thiamine $/ 50 \mathrm{ml}$. minimal medium. At $40 \mathrm{hr}$. $50 \mu \mathrm{g}$. thiamine $(a)$ or $50 \mu \mathrm{g}$. thiazole + $50 \mu \mathrm{g}$. pyrimidine $(b)$ were added. In control flasks there were no additions $(c)$. Strains used were: $\square$, thi-1 (56501 a); 0 , thi-1; thi-1o (17084-1-3); 0 , thi-3 (18558A); $\odot$, thi-1o+ (STA).

A test for the presence of the $t h i-1$ gene in Neurospora strains was devised by incubating optimally-grown mycelia cultures in the presence of $50 \mu \mathrm{g}$., each of thiazole and pyrimidine and measuring the thiamine synthesized by thiochrome fluorescence. The results are also shown in Fig. 1. With the exception of the thio-1o containing strain, these cultures produced similar amounts of thiamine from exogenous pyrimidine and thiazole. The thi-1o containing strain was unable to produce a significant amount of thiamine from its precursors. These results and the results in Table 3 indicate that this test is a valid means of detecting the presence of $t h i-10$ in strains independently of nutritional tests.

Other strains were tested for their ability to condense pyrimidine and thiazole. The experiment illustrated in Fig. 2 shows the relative synthetic rates of a few of these strains. The substrates of $100 \mu \mathrm{g}$. each of pyrimidine and thiazole were introduced into $48 \mathrm{hr}$.-old mycelial cultures grown in the standard optimal media. Both thi-1 and thi-3 strains show good rates of thiamine synthesis, 
while the thi-2 and thi-1o strains show very little increase in thiamine. Interestingly, even the SY $7 \mathrm{~A}(t h i-10)$ strain had relatively low activity in this test system, despite the fact that the growth of this wild-type strain was unaffected by thiamine.

\section{Table 3. The pyrimidine and thiazole condensing abilities of Neurospora mycelia}

Cultures were grown in $300 \mathrm{ml}$. Erlenmeyer flasks with $150 \mathrm{ml}$. minimal medium $+5 \mu \mathrm{g}$. thiamine $/ 100 \mathrm{ml}$. Cultures were shaken at $30^{\circ}$ for $41 \mathrm{hr}$., then $100 \mu \mathrm{g}$. of pyrimidine and thiazole were added aseptically and the cultures were shaken for another $12 \mathrm{hr}$.

\begin{tabular}{|c|c|c|c|c|c|}
\hline \multirow[b]{2}{*}{ Strain } & & \multicolumn{2}{|c|}{ No addition } & \multicolumn{2}{|c|}{$\begin{array}{l}\text { Pyrimidine } 100 \mu \mathrm{g} ., \\
\text { thiazole } 100 \mu \mathrm{g} .\end{array}$} \\
\hline & & $\begin{array}{l}\text { Final dry wt. } \\
\text { mycelium (mg.) }\end{array}$ & $\begin{array}{c}\text { Relative } \\
\text { thiochrome } \\
\text { fluor- } \\
\text { escence }\end{array}$ & $\begin{array}{l}\text { Final dry wt. } \\
\text { mycelium (mg.) }\end{array}$ & $\begin{array}{c}\text { Relative } \\
\text { thiochrome } \\
\text { fluor- } \\
\text { escence* }\end{array}$ \\
\hline 56501 a & thi-1 & $0 \cdot 386$ & 8 & $0 \cdot 372$ & 35 \\
\hline $56501-3-70 a$ & $t h i-1$ & $0 \cdot 449$ & $\mathbf{9}$ & 0.478 & 50 \\
\hline $56501-3-71 \mathrm{~A}$ & $\begin{array}{l}\text { thi-1; } \\
\text { thi-1o }\end{array}$ & $0 \cdot 350$ & 6 & $0 \cdot 400$ & 8 \\
\hline 56501-3-75a & $t h i-1$ & $0 \cdot 384$ & 6 & $0 \cdot 360$ & 34 \\
\hline $56501-3-77 a$ & thi-1 & $0 \cdot 378$ & 9 & $0 \cdot 4.55$ & 45 \\
\hline $56501-3-86 \mathrm{~A}$ & $t h i-1$ & $0 \cdot 370$ & 9 & $0 \cdot 400$ & 33 \\
\hline $56501-3-87$ A & $t h i-1$ & $0 \cdot 380$ & 7 & $0 \cdot 413$ & 32 \\
\hline $56501-3-88 a$ & $\begin{array}{l}\text { thi-1; } \\
\text { thi-1o }\end{array}$ & $0 \cdot 450$ & 8 & $0 \cdot 420$ & 9 \\
\hline $56501-5-(15-8)$ & thi-3 & 0.434 & 4 & 0.440 & 38 \\
\hline $56501-5-(15-5)$ & thi-1 & $0 \cdot 430$ & 8 & $0 \cdot 480$ & 40 \\
\hline $56501-5-(15-3)$ & thi-1 & $0 \cdot 448$ & 8 & 0.460 & 40 \\
\hline
\end{tabular}

* Relative fluorescence here is directly proportional to thiamine (thiochrome) concentration in the mycelium.

Since the nutritional response of a 'wild-type' strain was unmodified by the presence of $t h i-1 o$, it was of interest to study the effect of $t h i-1 o$ on the thi-3 nutritional phenotype. This was done by making crosses which would result in thi-3; thi-1o double mutants and testing the nutritional and thiamine synthesizing capacities of various random isolates. Results of two experiments are reported.

In the first experiment a thi-1; thi-3; thi-1o+ double mutant was crossed to thi-1o (SY7A), (cross 56501-7). Strains were randomly isolated. The following nutritional types of strains were found: 'wild', thi-1, thi-3, and strains which responded like thi-1;thi-1o. In thiamine-synthesizing tests, both the 'wild' and thi-3 types showed either high or low activity ( + or $-t h i-10$ ), while the strains which were like thi-1 nutritionally showed only high thiamine synthesizing abilities. All strains which responded nutritionally like thi-1; thi-1o doubles had low thiamine-synthesizing capacities. Typical thiamine-synthesizing abilities of some of these strains are shown in Table 4. These results are consistent with the idea that $t h i-10$ drastically lowers the ability of $t h i-3$ strains to condense pyrimidine and thiazole, without modifying 
their nutritional requirements. A similar decrease in synthetic capacity by thi-1o in thi-1 strains results in a change in nutritional requirements.

A second experiment was designed to show the interactions of thi-1o and thi-3 genes. Strain 18558 A $(t h i-3)$, which did not contain thi-1o, was crossed (cross 18558-1) to a thiamine-independent strain (56501-7-54a) which contained $t h i-10$ as shown by a lowered ability to condense pyrimidine and thiazole. Of the seventy random spores dissected from this cross, thirty-six were

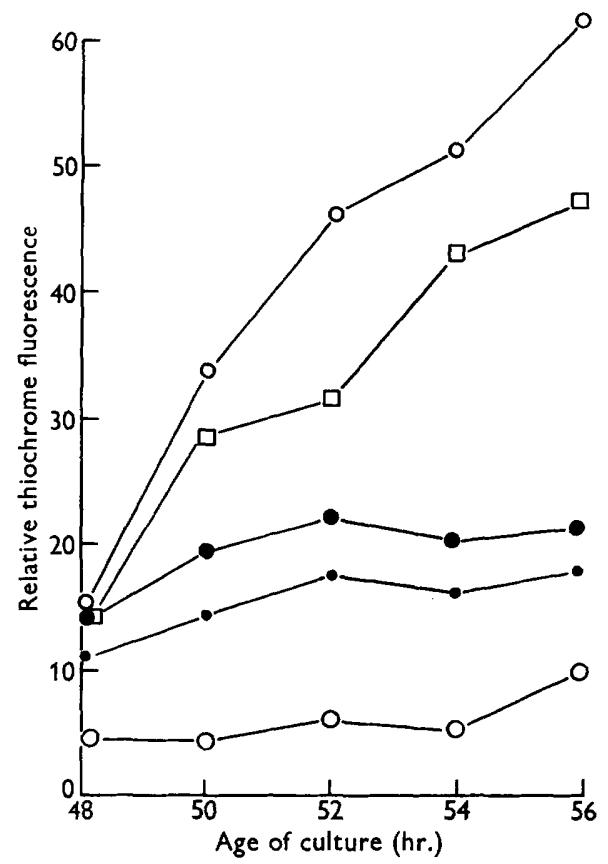

Fig. 2. Thiamine synthesis from pyrimidine and thiazole by Neurospora. Cultures were grown on $50 \mathrm{ml}$. minimal medium $+2.5 \mu \mathrm{g}$. thiamine. At $48 \mathrm{hr}$. $100 \mu \mathrm{g}$. thiazole + $100 \mu \mathrm{g}$. pyrimidine were added. Strains used were: $\square$, thi-1 (56501 a); 0, thi-1; thi-1o (17084-1-3); O, thi-2 (9185a); o, thi-3 (18558 A); •, thi-1o (Sy7 A).

wild and thirty-four were like thi-3 nutritionally. Several isolates were examined for their synthetic abilities and bound thiamine (thiamine pyrophosphate) was measured in terms of the relatively specific yeast cocarboxylase assay. The data given in Table 5 show the cocarboxylase-synthesizing abilities of thi-1o+, thi-3; thi-1o and thi-3 strains. In the longer growth and incubation of these cultures, thi-1o can be shown not to be a complete block. Nevertheless, under these conditions there is still at least a twofold difference in the synthetic performance of modified and unmodified strains. The thi-3; thi-1o strains are nutritionally similar to thi-3 in their ability to respond to exogenous thiazole as a source of thiamine.

It was thought that carboxylase activities in these strains might be a useful index of the presence of $t h i-10$ in its role as modifier of cocarboxylase synthesis from thiazole and pyrimidine. Yet, this test system was not applicable to optimally grown mycelia since maximal carboxylase activity is found in 
thio-1o strains. Table 5 includes the carboxylase activities of $t h i-10+$, thi-3; thi-1o and thi-3. These results indicate that thi-1o is not distinguishable in terms of the carboxylase activities of optimally grown strains. Carboxylase activity apparently does not reflect differences of internal cocarboxylase concentrations at these high cocarboxylase levels. The apocarboxylase in these mycelia is probably saturated with coenzyme at the high cocarboxylase

\section{Table 4. Thiamine-synthesizing abilities* of Neurospora isolates from cross 56501-7}

Cultures were grown in shake culture in $50 \mathrm{ml}$. of minimal medium $+2.5 \mu \mathrm{g}$. thiamine. At $40 \mathrm{hr}$. cultures were supplemented with $50 \mu \mathrm{g}$. each of pyrimidine and thiazole, shaken an additional $12 \mathrm{hr}$, then harvested.

Additions at $40 \mathrm{hr}$.

None Thiamine $\begin{aligned} & \text { Thiazole }+ \\ & \text { pyrimidine }\end{aligned}$

\begin{tabular}{|c|c|}
\hline Strain & $\begin{array}{l}\text { Nutritional } \\
\text { phenotype } \dagger\end{array}$ \\
\hline $56501-7-20$ & thi-1 \\
\hline 23 & thi-1 \\
\hline 34 & $t h i-3$ \\
\hline 64 & thi-3; thilo \\
\hline 72 & thi-1; thi-1o \\
\hline 75 & thi-1; thi-1o \\
\hline 76 & thi-1; thi-1o \\
\hline 77 & thi-3; thi-1o \\
\hline $56501-3-69$ & thi-1; thi-1o \\
\hline 71 & thi-1; thi-1o \\
\hline 73 & thi-1; thi-1o \\
\hline 87 & thi-1 \\
\hline SY7A & thi-1o \\
\hline $9185 a$ & thi-2 \\
\hline
\end{tabular}

Relative thiochrome concentrations*

*Values in table are in relative thiochrome concentrations (see methods).

$\dagger$ thi-3; thi-1o doubles are nutritionally identical to $t h i-3$ strains; thi-1; thi-1o strains are quantitatively like thi-1 (high thiamine requirement), but they will eventually show growth on thiazole- and pyrimidine-containing media at times when the minimal cultures are still blank.

Table 5. Cocarboxylase synthesis and carboxylase activity in modified and unmodified Neurospora strains

Cultures were grown with shaking in $50 \mathrm{ml}$. of minimal medium $+2 \cdot 5 \mu \mathrm{g}$. thiamine in $125 \mathrm{ml}$. Erlenmeyer flasks at $30^{\circ}$. After $46 \mathrm{hr}$. of growth, solutions containing $50 \mu \mathrm{g}$. thiamine, or $50 \mu \mathrm{g}$. each of pyrimidine and thiazole, sterilized by filtration were added and the cultures were shaken an additional $14 \mathrm{hr}$. and harvested.

Values in the table are: $a=\mu \mathrm{g}$. cocarboxylase/g. dry wt. mycelium; $b=$ carboxylase activity as $\mu \mathrm{l}$. $\mathrm{CO}_{2} / 25 \mathrm{mg}$. dry wt. mycelium $/ 5 \mathrm{~min}$. (average of three readings).

Additions at $46 \mathrm{hr}$.

\begin{tabular}{|c|c|c|c|c|c|c|c|}
\hline \multirow[b]{3}{*}{ Strain } & \multirow[b]{3}{*}{$\begin{array}{c}\text { Genetic } \\
\text { composition }\end{array}$} & \\
\hline & & \multicolumn{2}{|c|}{ None } & \multicolumn{2}{|c|}{$\begin{array}{l}\text { Thiazole 50 } \mu \mathrm{g} .+ \\
\text { pyrimidine } 50 \mu \mathrm{g} \text {. }\end{array}$} & \multicolumn{2}{|c|}{ Thiamine $50 \mu \mathrm{g}$} \\
\hline & & $a$ & $b$ & $a$ & $b$ & $a$ & $\vec{b}$ \\
\hline STA & $t h i-1 o+$ & 37 & 158 & 105 & 172 & 105 & 168 \\
\hline $18558-1-9$ & thi-3; thi-1o+ & 8 & 78 & 86 & 140 & 92 & 143 \\
\hline $18558-1-8$ & thi-3;thi-1o & 16 & 105 & 54 & 147 & 96 & 150 \\
\hline $18558-1-10$ & thi-3; thi-1o & 19 & 110 & 41 & 110 & 101 & 112 \\
\hline
\end{tabular}


concentrations resulting from optimal growth. From these experiments and others it was seen that the presence of thi-1o suppresses the condensation of pyrimidine and thiazole in every strain tested. The nutrition of $t h i-1$ strains is modified by thi-1o, while the nutritional responses of wild-type (Table 6) and $t h i-3$ strains are not impaired by thi-1o. Consequently the only means of detecting thi-1o in thi-3 and wild-type stocks is a test of the synthetic abilities of their mycelia.

Table 6. Growth response of Neurospora strains thi-1o and thi-1o+ to thiamine-active substances

The strains were grown $45 \mathrm{hr}$. at $30^{\circ}$ in $125 \mathrm{ml}$. Erlenmeyer flasks containing $20 \mathrm{ml}$. minimal medium + supplements indicated. Figures represent dry weight of mycelium in mg.

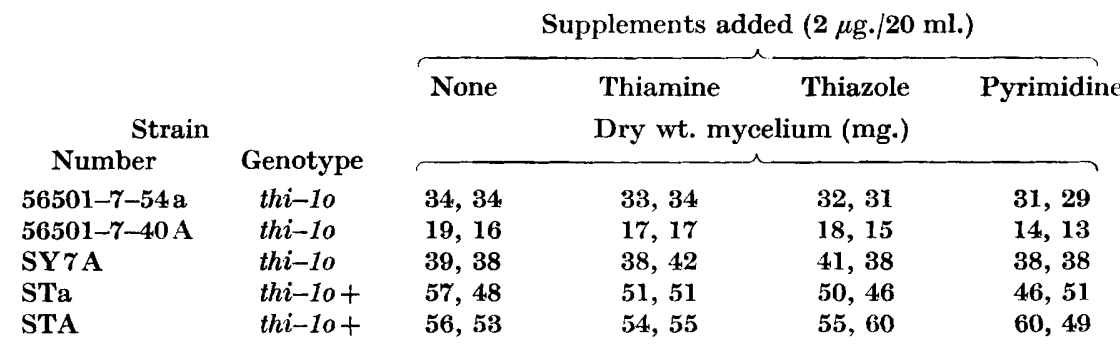

Genetic relationships of thi-1o

Since thi-1o expresses itself as a nutritional anomaly only in the presence of thi-1, a cross was made (cross 56501-17) between two thi-1 strains, one of which contained thi-1o. In fourteen complete asci tested, thi-1o showed only first division segregation, which indicated a map location close to the centromere. The 2:2 segregation data found indicated that the thi-1o character was associated with a single gene. Additionally, the data from the original cross (cross 56501-3) in which thi-1o segregated from SY $7 \mathrm{~A}$ are also consistent with the hypothesis that thio-1o was a single gene in this 'wild-type' stock.

When thi-1o was detected in thi-1 stocks, it became important to know whether it was present in the various other thiamine-requiring stocks. The presence of $t h i-10$ in $t h i-2$ or $t h i-4$ stocks would make obtaining and studying of double mutants with $t h i-1$ extremely difficult.

A cross of a thi-1; thi-1o strain by a thi-2 strain (cross 56501-6) was made, and a number of recombinant thi-1 strains were recovered which did not contain $t h i-1 o$, thus showing that $t h i-1 o$ is not present in the $t h i-2$ parent $(9185 a)$, and that thi-2 is not allelic with thi-1o. In a cross of thi-4 by thi-1 (without thi-1o) (cross 85902-3), the randomly selected unmodified thi-1 types were approximately equal to the wild types suggesting there are no modifiers in thi-4 not linked to thi-4.

The possibility that thi-1o might be linked to or allelic with thi-4 was considered because of the similarity of action of these loci. From the linkage data summarized by Barratt et al. (1954), thi-1 is in linkage group I, thi-2 and thi-4 are in group III, while thi-3 is in group VII. A cross of a $t h i-4$ strain by $t h i-1$; thi-1o strain (cross 85902-2) was made, and of fifty-five thiamine-requiring random isolates, not one was a recombinant thi-1; thi-1o+ nutritional 
type. Of these fifty-five isolates forty were thi-4-containing strains, and fifteen were $t h i-1$; thi-1o parental types. The parental $t h i-1$; thi-1o types could be differentiated from isolates which contained thi-4 because the thi-1; thi-1o eventually grew on test media containing pyrimidine and thiazole in 5-6 days at $30^{\circ}$. Strains containing the thi-4 gene did not grow under comparable conditions. These results were in agreement with the proposed parental genotypes. These results are also consistent with the location of thi-1o in linkage group III. Since neither $t h i-4$ or $t h i-10$ have shown recombination with their centromere nor with each other, and since their function is at the same metabolic step, their allelism is strongly suggested.

\section{DISCUSSION}

Considerable attention has been paid to the mechanism of gene suppressor action in Neurospora since the initial work of Houlahan \& Mitchell (1947). This is mainly due to the relative ease of obtaining this type of modifier. Relatively little attention has been directed to other types of modifiers in Neurospora. There is no reason at present to believe that the basis of suppressor action is fundamentally different from that of other modifiers. The difference may only be a definitional one concerning the direction (towards or away from wild-type phenotype) of the modification rather than a fundamental difference in mechanism.

Modifier action can be considered as operating at two levels: $(a)$ at the enzyme-forming level where apoenzyme specificity is determined; $(b)$ at the enzyme activity level, where co-factor, $\mathrm{pH}$, substrate and other factors are involved. While some of these inter-relationships have been shown in suppressor systems (Yanofsky 1956) the examples from other modifier systems are limited. Haskins \& Mitchell (1952) and Newmeyer \& Tatum (1953) studied modifiers in Neurospora which apparently have their effect at the substrate level. These investigators independently found that the phenotype of a gene $(n t)$, which is involved in nicotinic acid and tryptophan biosynthesis, is affected both qualitatively and quantitatively by the presence of modifying genes. Strauss (1956) studied the gene at which acts as a modifier of succinate $(s u c)$ requiring strains. Strains containing at; suc are unable to grow immediately on acetate, while suc strains can use this substrate.

The gene $t h i-10$ appears to illustrate gene modifier action at the substrate level. The thi-1o mechanism of modification in the strains where it has been studied is clearly that of modulating the ability to condense pyrimidine with thiazole. Still thi-1o is a modifier in the strictest sense, because its primary phenotypic expression is not discernible in terms of the wild-type nutritional phenotype, while it specifically modifies the nutritional phenotype of the thi-1 strains tested. The fact that thiamine mutants derived from only 17084 and 56501 strains are modified by thi-1o is in agreement with their probable allelism. The thi-1o; thi-1 mutant strains are similar to at; suc strains in that they eventually grow on thiazole + pyrimidine just as at; suc strains will eventually grow on acetate. As with $t h i-10$ strains, the at strains show a wildtype growth rate. 
The gene thi-1o is also of interest as a probable isoallele of $t h i-4$. In this role it represents a class of subthreshold alleles in a series which would range from mutants possessing a complete block through 'leaky-mutants' to mutants with no auxotrophic requirements at all. Members of this last class are most poorly represented in the catalogue of mutant types because simple nutritional techniques are inadequate to detect them. Subthreshold alleles (or wild-type isoalleles) can be picked up by specific physiological techniques as with the sub-threshold tryptophan mutants studied by Giles (1955). Alternatively, as suggested by the work of Goldschmidt \& Piternich (1956) with the effects of subthreshold alleles on phenocopies in Drosophila, and as indicated by the work with $t h i-10$, these isoalleles may be detected by their interaction with other genes like $t h i-1$ which can lower the nutritional threshold to a point where the subthreshold gene can express itself.

Part of doctoral thesis submitted to the Department of Biological Sciences, Stanford University, Stanford, California, U.S.A.

\section{REFERENCES}

Barratt, R. W., Newmeyer, D., Perkins, D. D. \& Garnjobst, L. (1954). Map construction in Neurospora crassa. Advanc. Genet. 5, 1.

Beadle, G. W. \& Tatum, E. L. (1945). Neurospora II. Methods of producing and detecting mutations concerned with nutritional requirements. Amer. J. Bot. 32, 678.

Eberhart, B. M.(1956). The Biochemical Genetics of Thiamine Metabolism in Neurospora crassa. Doctoral thesis, Stanford University.

GrLes, N. H. (1955). Forward and back mutation in specific loci in Neurospora. Brookhaven Symp. Biol. 8, 103.

Goldschmidt, R. B. \& Piternick, L. K. (1956). New experiments on chemical phenocopies. Proc. nat. Acad. Sci., Wash. 42, 299.

Harris, D. L. (1953). Biosynthesis of thiamine in Neurospora. Fed. Proc. 12, 214.

HARris, D. L. (1955). Alternative pathways in thiamine biosynthesis in Neurospora. Arch. Biochem. Biophys. 57, 240.

Haskins, F. A. \& Mitchell, H. K. (1952). An example of modifying genes in Neurospora. Amer. Nat. 86, 231.

Houlahan, M. B. \& Mrtchell, H. K. (1947). A suppressor in Neurospora and its use as evidence for allelism. Proc. nat. Acad. Sci., Wash. 33, 223.

Newmeyer, D. \& Tatum, E. L. (1953). Gene expression in Neurospora mutants requiring nicotinic acid or tryptophan. Amer. J. bot. 40, 392.

Stiller, E. T. (1950). In Vitamin Methods, I, p. 95. Ed. P. Gyorgy, New York: Academic Press, Inc.

Strauss, B. S. (1956). The nature of the lesion in the succinate requiring mutants of Neurospora crossa: interaction between carboxylase and nitrogen metabolism. J. gen. Microbiol. 14, 494.

TAtum, E. L. \& Bell, T. T. (1946). Neurospora. III. Biosynthesis of thiamin. Amer. J. Bot. 33, 15.

Westenbrink, H. G. K. \& Steyn-Parvé, E. P. (1950). Methods for the determination of diphosphothiamine. Z. Vitaminforsch. 21, 461.

WestergaARD, M. \& Mitchell, J. K. (1947). Neurospora. V. A synthetic medium favouring sexual reproduction. Amer. J. Bot. 34, 573.

YANofsky, C. (1956). Gene interactions in enzyme synthesis. In Enzymes, Units of Biological Structures and Function, p. 147. Ed. Gaebler, O. H. New York: Academic Press. 